American Journal of Applied Sciences 9 (7): 1079-1084, 2012

ISSN 1546-9239

(C) 2012 Science Publications

\title{
The Coastal Current of the Andaman Sea Revealed by Reprocessed Observations
}

\author{
${ }^{1,2}$ Sakharin Suwannathatsa, ${ }^{1,2}$ Prungchan Wongwises, \\ ${ }^{1,2}$ Worachat Wannawong and ${ }^{3}$ Suphat Vongvisessomjai \\ ${ }^{1}$ Joint Graduate School of Energy and Environment, \\ King Mongkut's University of Technology Thonburi, Bangkok 10140, Thailand \\ ${ }^{2}$ Center of Excellence on Energy Technology and Environment, \\ S\&T Postgraduate Education and Development Office (PERDO), Bangkok 10140, Thailand \\ ${ }^{3}$ Team Consulting Engineering and Management Co., Ltd., \\ TEAM Building, Nuan Chan Road, Bangkok 10230, Thailand
}

\begin{abstract}
Problem statement: The surface currents in the Andaman Sea are observed and quantified by many studies in opposite of the local coastal current that is unclear. Knowing the contributor to this local current improves the simulation work in the most accurate way. This study reviews reprocessed observations from satellites and creates an oceanic model by taking data of 1995 to generally explain the character of local coastal currents. Approach: The reprocessed data from satellite altimeter and Acoustic Doppler Currents Profilers (ADCP) ship are reviewed. The oceanic models based on the data of calm weather in 1995 are created to explain the character of coastal currents and associated intra-seasonal cycles in the no storm condition of other years. Results: Reprocessed satellite data and ADCP after comparing with models reveal the effects of the local wind along the coast and Rossby waves (triggered by Elman pumping or radiated by Equatorial Kelvin waves). That causes the intraseasonal coastal current instead of regional monsoonal winds. Conclusion/Recommendations: The effects of regional monsoon winds are less than local winds and meso-scale eddies in the coastal current in the Andaman Sea. The simulation based on regional winds can not explain the coastal current in the no storm condition. Local winds and meso-scale eddies need to take into account in the model in order to capture these coastal currents.
\end{abstract}

Key words: Andaman sea, bay of Bengal, coastal current, satellite data analysis, reprocessed observations, oceanic model

\section{INTRODUCTION}

The Andaman Sea is a famous tourist attraction for the last 20 years that currents during high monsoons are the prohibition of access for sometime during a year. Well understanding these currents allows us to forecast the open windows and consequently ease the tourism. Even the Andaman Sea has long been studied and known that heavily seasonal forcing in agreement with the reversing monsoon winds but it has the unique circulation (Hacker et al., 1998). Recent observational data from satellites give the images of these intraseasonal cycles.

\section{MATERIALS AND METHODS}

Past observations: In the early day, scientists observed the currents in the Andaman Sea by hydrographic ships.
The satellite-tracked drifter buoys reveal dramatically reversal winds and currents by main seasonal monsoons which are North-East wind in the winter (NovemberFebruary) and the South-West wind in the raining season (July-October). The transition is between these two windows and vary geographically from year to year. Approaching the North-East monsoon end, the surface water of Andaman Sea seems to be warmer, more saline and reaches the peak in May, in contrast, the end of South-West monsoon is the time highly stratified and mix layers and cool and warm surface and perturbation are observed. The river run-off gives the greatest drop of salinity in November and December and flows toward to the Bay of Bengal (Potemra et al., 1991).

Reprocessed observations: ADCP ships, hydrographic observations and the satellite altimeter are reprocessed 
and carefully reviewed in the domain. The currents of the Bay of Bengal are influenced by Reginal winds and meso-scale eddies. Reprocessing the altimeter data gives higher resolution along shore and the understanding in coastal currents (Durand et al., 2009).

As a result, local along shore winds and Ekman pumping are as important as seasonal winds dominating to coastal currents (Shenoi, 2010). The coastal current could also flow in opposite the direction of offshore currents (Durand et al., 2009).

Simulation: The ocean model with the domain of the Bay of Bengal $\left(78^{\circ} \mathrm{E}-102^{\circ} \mathrm{E}, 0^{\circ}-26^{\circ} \mathrm{N}\right)$ (Fig. 1) has been created from; the 1 Arc-minute terrain data, ETOPO1 (Amante and Eakins, 2009), World Ocean Atlas 2005, WOA05 temperature/salinity (Levitus et al., 1994), ECMWF wind (Viterbo and Betts, 1999). The dimension of this sigma-coordinate, free surface, primitive equation model is $96 \times 104$ grid points on horizon and 16 layers in the vertical direction. It is bounded by 3 enclosures on the east, west and north and open on the south assuming as close boundary. The 3-D sector (Fig. 2) Has been created to spot an error and level age before defining the temperature and salinity for individual grid point at each layer (Wannawong et al., 2010). The temperature, salinity and wind data of 1995 are selected because they represent the calm weather. Lastly the surface wind of January, May and October 1995 are inputted to drive the surface current. In May (Fig. 3), it is a transition period when South-West monsoons coming to replace the North-East monsoon. The winds do not laminar flow and there are many turbulents scattering within the domain. This cause a weak surface current during this transition period. In October (Fig. 4), the South-West wind is strongest during a year. This drive Northward flows in the domain whereas January (Fig. 5 and 6) has a laminar North-East wind throughout the domain driving the water southeastward.

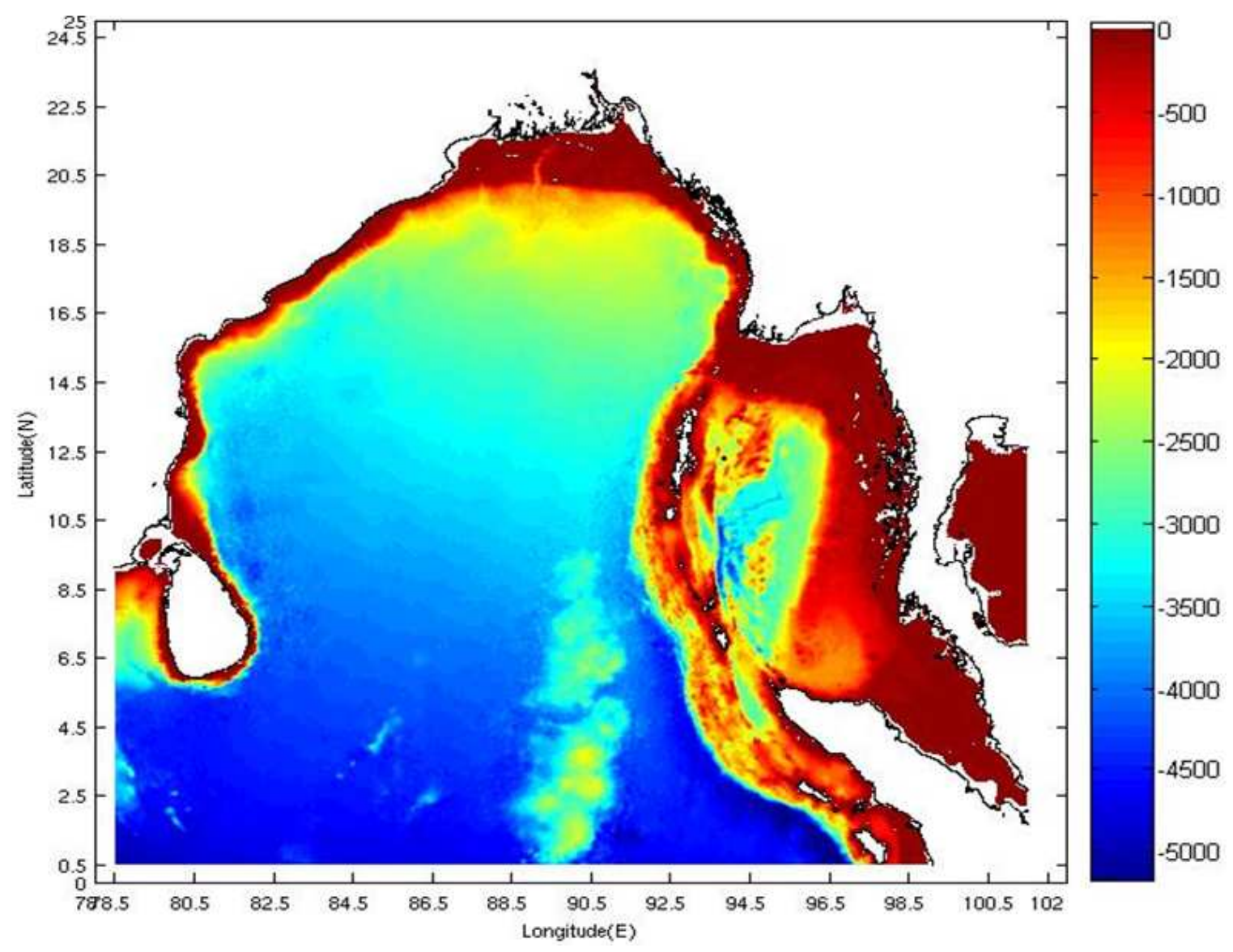

Fig. 1: The map of the the study area covers the Bay of Bengal 


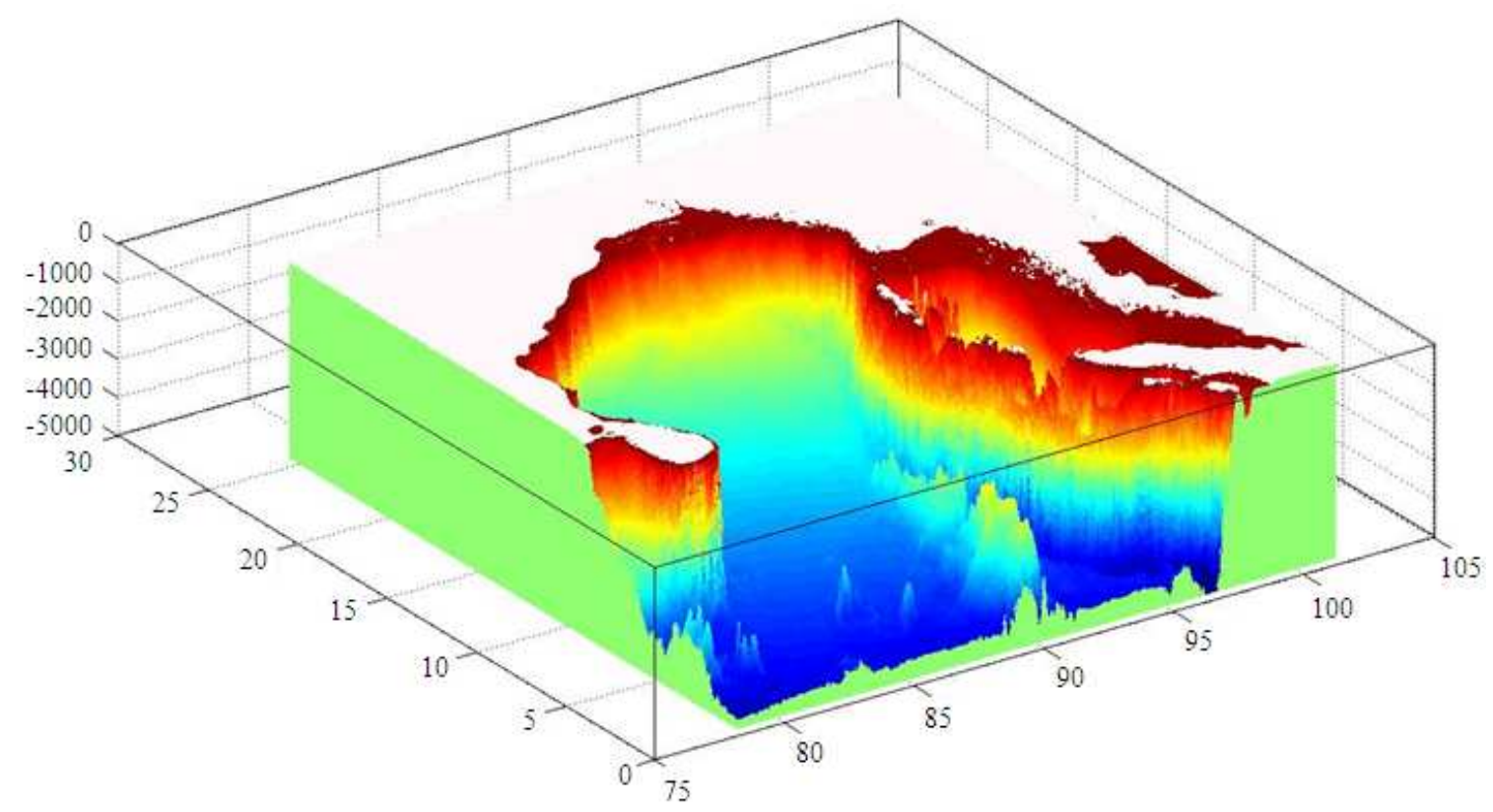

Fig. 2: Perspective view (3-D) of the domain

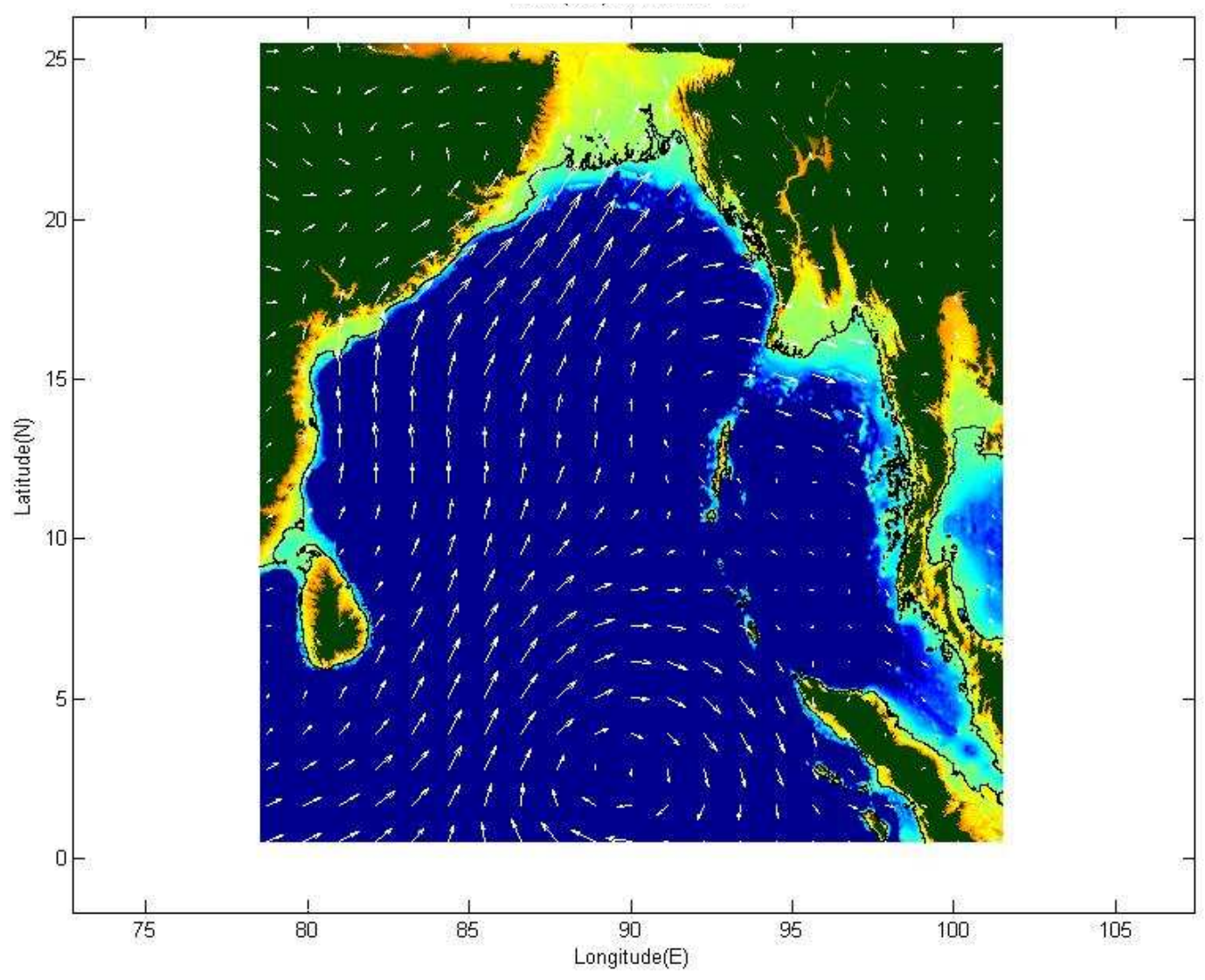

Fig. 3: Monsoon-transition regional winds in May 1995 (ECMWF) 1081 
Am. J. Applied Sci., 9 (7): 1079-1084, 2012

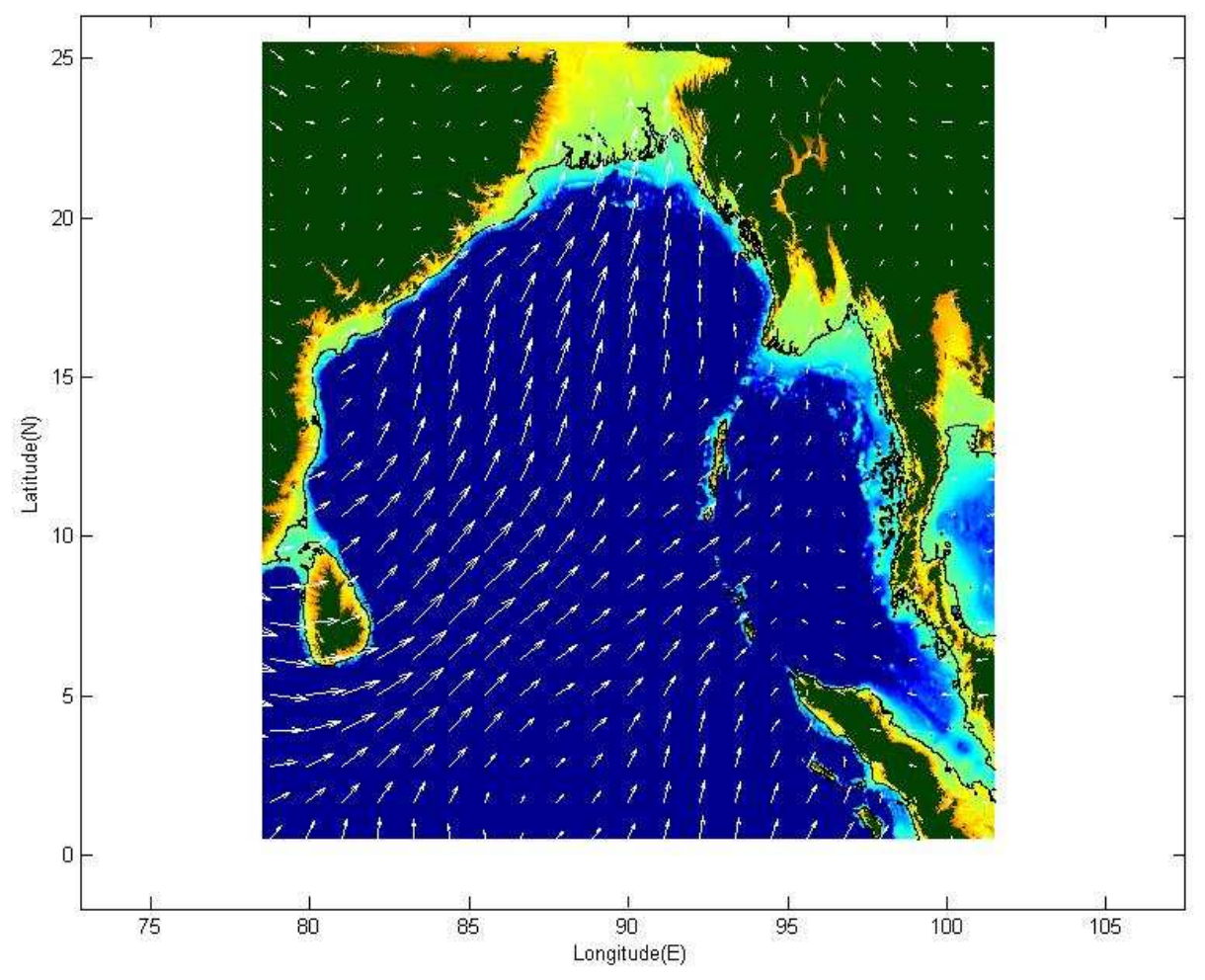

Fig. 4: South-West monsoon regional winds in October 1995 (ECMWF)

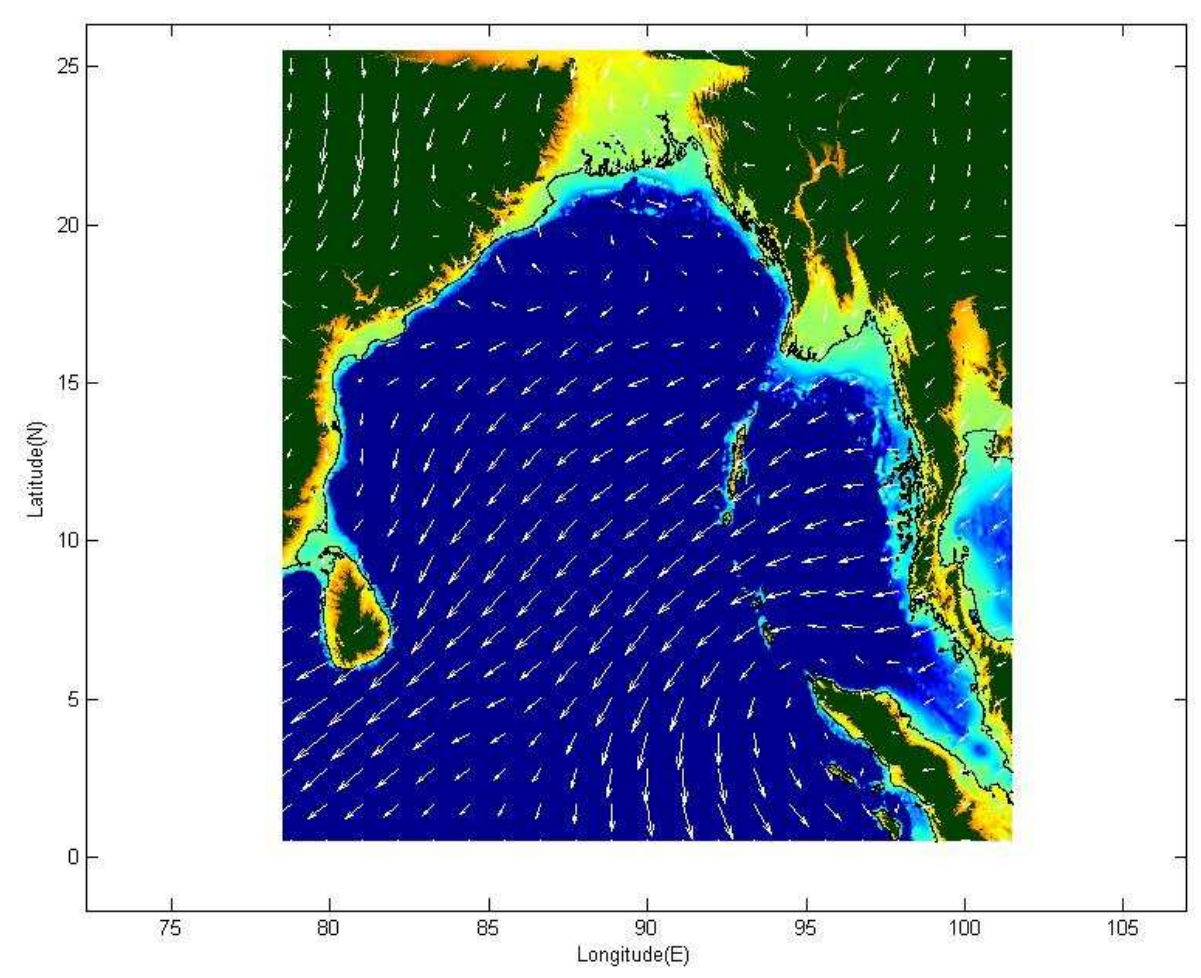

Fig. 5: North-East monsoon regional winds in January 1995 (ECMWF) 1082 


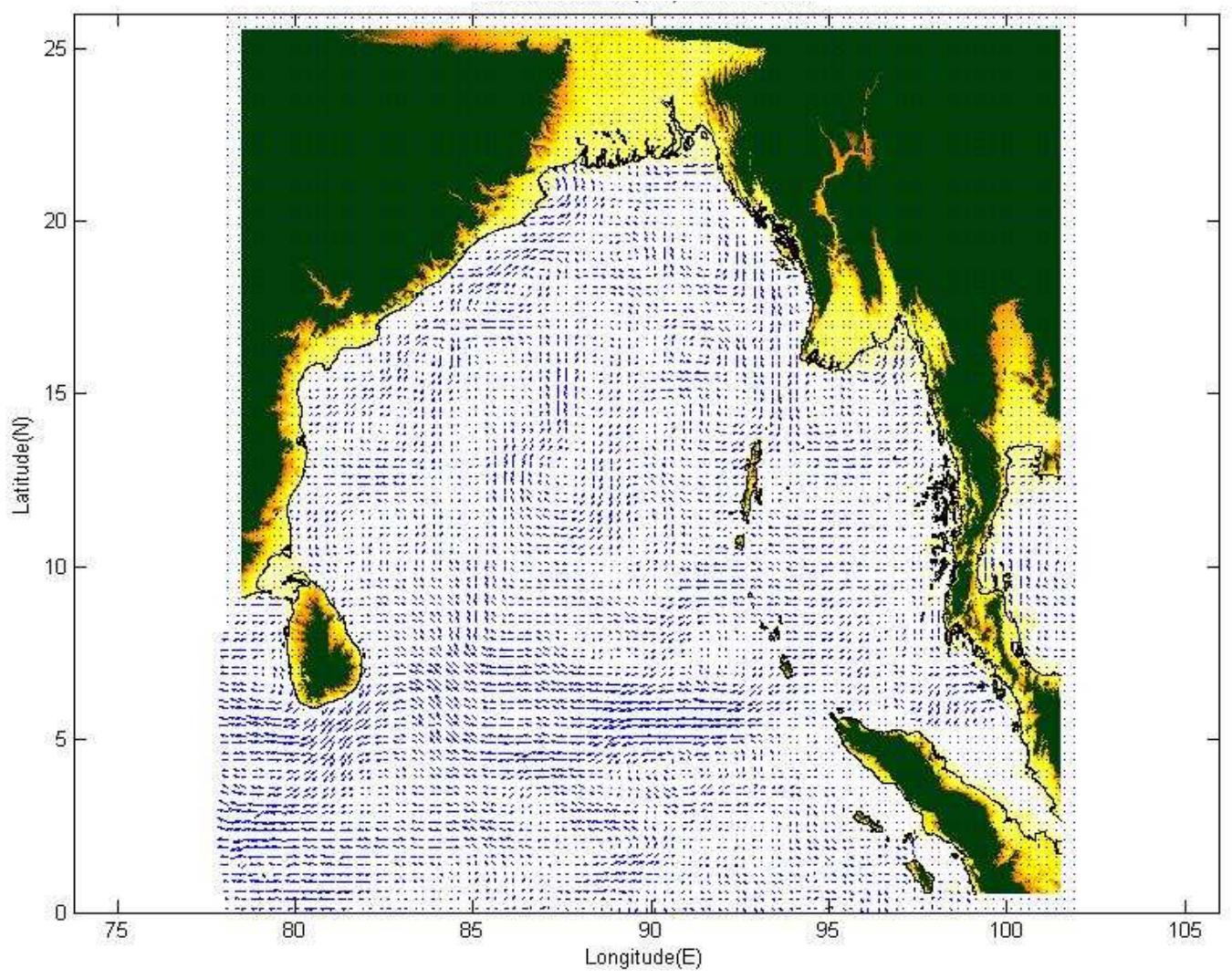

Fig. 6: The regional wind-driven currents by oceanic model in January 1995

\section{RESULTS}

From reprocessed satellite data and ADCP, the transition period from winter to summer in March to May, Regional currents are strongest but the regional wind is weakest in the year; equatorial Kelvin waves move northward and propagate into domain at the North of Sumatra together with the divergence of Ekman transport. This cause Rossby wave contributes to the interior Bay of Bengal in driving the strong North-Eastward current of the seasonal subtropical gyre (Shenoi, 2010). This agrees with simulation results that strong Nort-Eastward current is observed at the North of Sumatra but going weaker approaching the coast. In the raining season (July October), the reprocessed data and ADCP (Fig. 7) Suggest that is much weaker and turbulent, the local alongshore winds contribute many turbulent currents on the west of domain and they tend to move southward. These also draw the fresh water run-off from the river at the top of the Bay to the coast of India. The ocean model shows the same result. A few turbulents and unpattern flows occur in the Andaman Sea but very weak currents near shore are observed.

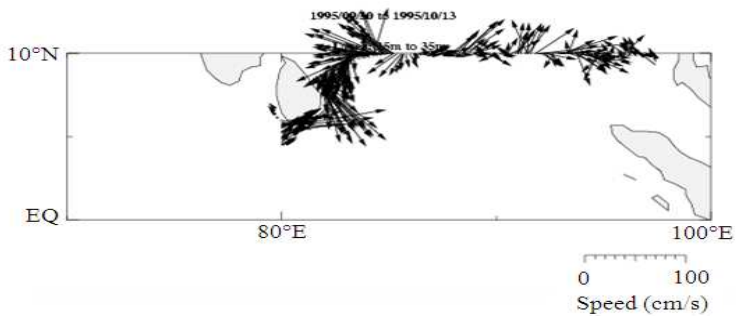

Fig. 7: ADCP ship data from R/V Knorr 30th Sep. 13th Oct. 1995, 25-35 m. depth

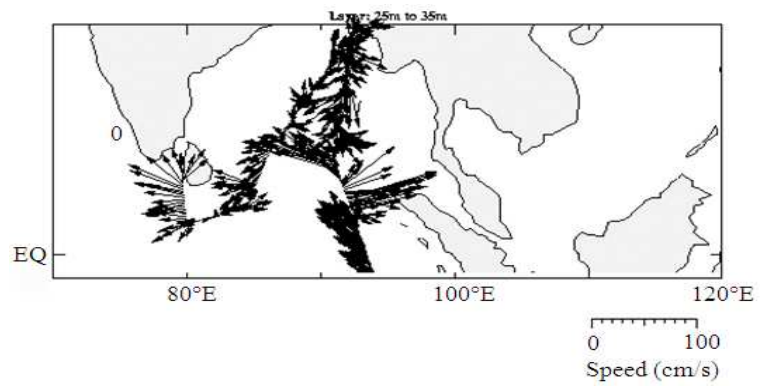

Fig. 8: ADCP ship data from R/V Knorr 24th Jan. -5th Mar. 1995, 25-35 m depth 
In North-East monsoon from October to January, reprocessed data and ADCP (Fig. 8) Reveal Ekman currents and the local alongshore winds force the southward regional currents (Shenoi, 2010) while the simulation suggests the southwestward current but relatively weak.

\section{DISCUSSION}

The review of reprocessed data and ADCP gives the agreed results with simulation at the mid Andaman sea where the water is deep. They have the same current pattern both monsoons and transition seasons. In the coastal area, currents can be seen by reprocessing data and ADCP but simulation shows a very weak currents or disappear on the coast in many months.

\section{CONCLUSION}

The coastal currents in BOB are influenced by local coastal winds and Rossby waves triggered by Ekman currents or radiated by equatorial Kelvin waves. This is as important as seasonal winds. The shallow currents flow northeastward of equatorial Kelvin waves, Ekman pumping and Rossby waves from March to May. Local alongshore winds respond in many turbulent coastal currents with a tendency to move southward and draw in the fresh from the top of domain southward from June to September. Both Ekman current and coastal winds drive them southward in the raining season and winter. In conclusion, field measurements and local-scaled simulation that take local winds, Rossby and Kelvin waves and Ekman currents into account are the way forward in capturing these coastal currents in more detail rather than the large-scale regional wind-driven oceanic model.

\section{ACKNOWLEDGMENT}

The team gratefully acknowledges the Center of Excellence for Energy Technology and Environment, Ministry of Education, Thailand for a financial support. The appreciation is given to Postdoctoral Researcher at Earth System Sciences research cluster (ESS), JGSEE for the info and guidelines and Chortip Siwapornanan, a lecturer at Rajamangala University of Technology Rattanakosin for data formatting and visualization.

\section{REFERENCES}

Amante, C. and B.W. Eakins, 2009. ETOPO1 1 ARCMinute Global Relief Model: Procedures, Data Sources and Analysis. 1st Edn., National Oceanic and Atmospheric Administration, Boulder, Colo., pp: 19.

Durand, F., D. Shankar, F. Birol and S.S.C. Shenoi, 2009. Spatiotemporal structure of the East India coastal current from satellite altimetry. J. Geophys. Res., 114: 18-18. DOI: 10.1029/2008JC004807

Hacker, P., E. Firing, J. Hummon, A.L. Gordon and J.C. Kindle, 1998. Bay of Bengal currents during the northeast monsoon. Geophy. Res. Lett., 25: 2769-2772. DOI: 10.1029/98GL52115

Levitus, S., T.P. Boyer and J. Antonov, 1994. World Ocean Atlas: 1994 Interannual Variability of Upper Ocean Thermal Structure. 1st Edn., DIANE Publishing, ISBN-10: 0788130781, pp: 176.

Potemra, J.T., M.E. Luther and J.J. O'Brien, 1991. The seasonal circulation of the upper ocean in the bay of Bengal. J. Geophys. Res., 96: 667-683. DOI: 10.1029/91JC01045

Shenoi, S.S.C., 2010. Intra-seasonal variability of the coastal currents around India: A review of the evidences from new observations. Int. J. Geo Marine Sci., 39: 489-496.

Viterbo, P. and A.K. Betts, 1999. The impact of the ECMWF reanalysis soil water on forecasts of the July 1993 Mississippi flood. J. Geophy. Res., 104: 361-366. DOI: 10.1029/1999JD900449

Wannawong, W., U.W. Humphries, P. Wongwises, S. Vongvisessomjai and W. Lueangaram, 2010. Numerical analysis of wave and hydrodynamic models for energy balance and primitive equations. Int. J. Math. Stat. Sci., 4: 365-375. 